\title{
XLVI. On certain large crystals of enstatite found by W. C. Brögger and H. H. Reusch at Kjorrestad near Bamle, South Norway
}

\section{W.C. Brögger \& G. vom Rath}

To cite this article: W.C. Brögger \& G. vom Rath (1876) XLVI. On certain large crystals of enstatite found by W. C. Brögger and H. H. Reusch at Kjorrestad near Bamle, South Norway, Philosophical Magazine Series 5, 2:12, 379-387, DOI: 10.1080/14786447608639121

To link to this article: http://dx.doi.org/10.1080/14786447608639121

曲 Published online: 13 May 2009.

Submit your article to this journal $[\pi$

Џll Article views: 2

Q View related articles $₫$ 
ever, to be considered that this action is always towards the interior of the substance, and that the induction of electricity depends on the difference between the disturbances at the two positions at which the radiant cuts the surface of the body, which difference arises from the variation of the intensity of the action according to the law of the inverse square. It is evident that, although the radiants may be effective in producing motion of the atoms in the superficial stratum by reason of the variation of atomic density that subsists there, they may still be of an orderw hich, like light-and heat-radiants, produce no movement of the body as a whole.

Cambridge, October 17, 1876.

XLVI. On certain large Crystals of Enstatite found by W. C. Brögger and H. H. Reusch at Kjorrestad near Bamle, South Norway. Memoir by W. C. BRöGGER of Christienia and G. vom KaTH of Bonn*.

[Plate IV.]

THERE are few minerals which offer an equal interest, 1 from the point of view of the progressive development of our knowledge of them, with the two magnesian silicates, enstatite, $\mathrm{MgSiO}_{3}$, and olivine, $\mathrm{Mg}_{2} \mathrm{SiO}_{4}$. It is well known that our knowledge of the latter mineral, in proportion as it is increased, has recognized its abundance and importance. At first found almost exclusively in volcanic rocks and in small crystals, olivine has since been met with in platonic and metamorphic rocks, the "serpentine crystals" of Snarum having been recognized as pseudomorphs after olivine. This mineral further acquires a really universal importance through its presence in meteorites.

Nearly the same may be said of enstatite. Its distribution and its importance have hitherto been less recognizable than in the case of olivine. Professor Kenngott, nearly twenty years ago, gave the name of enstatite to a mineral from Mount Zdjar in Moravia, the composition of which von Hauer determined as that of a normal silicate, $\mathrm{MgSiO}_{3}$ ( Akad. Wien, vol. xvi. p. 162, 1855). Professor Des Cloiseaux showed by means of optical researches that the crystalline system of enstatite is rhombic, and established the difference between augite and enstatite (Bull. Soc. Gieol. vol. xxi. p. 105). Professor Rammelsberg first proved by chemical analysis that enstatite is a constituent of meteorites, the stone of Bishopsville (Monatsber. Akad.

* Communicated by the Crystallometric Association. Received Octo. ber $9,-$ Read October 27,1876 . 
Berlin, 1861). Professor N. Story Maskelyne found this mineral in the Busti meteorite (Trans. Roy. Soc. clx. 189). Professor von Lang showed, in an admirable investigation, how rich were the combinations of the enstatite of the Breitenbach meteorite. Nearly at the same time vom Rath determined the crystals of hypersthene of Laach. The specimens from both these sources, cosmical and terrestrial, have absolutely the same angles. Implanted crystals of enstatite presenting freely formed crystalline faces had hitherto been unknown in plutonic rocks. It might be thought that if they could be found they might astonish us by their gigantic size, like the olivines of Snarum; and in this expectation we are not disappointed.

In the apatite mine of Kjorrestad between Krageröe and Langesund, in the autumn of the year 1874, enstatite was discovered in crystals of a size reached only by very few minerals. The locality where the great enstatite crystals have been found is one of those numerous apatite veins of Southern Norway. The main rock of this part of the coast is mica and amphibole slate, in which the apatite veins are included. Their predominating mineral is amphibole.

In the vicinity of these normal veins there is to be found at the Hankedalsvand, not far from Vestre Kjorrestad, an isolated deposit, as a thick lode constituted principally of large crystals of enstatite and enormous masses of rutile. There was not much apatite, but some greenish-white mica and talc; and for this reason apatite was obtained only for a short time. The enstatite crystals, from 0.3 to 0.4 metre in size, had been thrown away unheeded, till they were discovered by Brögger and Reusch in their researches on the apatite beds (Zeitschr. d. deutsch. geol. Gesellsch. vol. xxvii. p. 646, 1875). As the mine of Vestre Kjorrestad had been already abandoned, the investigations of the discoverers were confined to the matter thrown out.

The enstatite crystals, occurring in more or less elongated columnar forms always broken at one end, were no doubt originally implanted on the wall of the lode. The space between the gigantic enstatite crystals was filled with silver-white or light-green talc. Also in the interior, and principally in the decomposed crust of the enstatite, we see minute scales of talc, lying in planes parallel to the prismatic faces, or oftener to the brachypinakoid, formed evidently by a metamorphosis of the enstatite.

The new crystals excite our attention at first by their size. Several crystals attain a magnitude of 20 centims. in length and in breadth. One of the two largest specimens measures 
38 centims. in length, 26 in breadth, 13 in thickness; the other one, notwithstanding its being broken at both ends, is still 40 centims. long.

The crystals show a predominating vertical rhombic prism, whose edges are nearly rectangular. The makropinakoid is much developed, whilst the brachypinakoid is only small. An evident rhombic symmetry is seldom to be recognized on the summits of the crystals ; it offers, on the contrary, a pseudomonoclinic appearance. A very characteristic feature of the crystals is the great number of often repeated faces, and with small inclinations which form a shallow vaulted summit. We shall return to the study of the crystalline form after a brief sketch of the physical and chemical properties. The surface of the crystals offers a steatitic appearance; the faces are dull. This steatitic crust is only thin, reaching at the utmost 10 millims. into the interior. There are two perfect cleavages, parallel to the prismatic faces; the third, parallel to the brachypinakoid, is imperfect. The lustre of the first two is pearly, whilst that of the imperfect cleavage is only glistening. Numerous undulated fissures seen on the cleavage-faces are connected with the metamorphosis into steatite. It is very interesting by means of the microscope to observe the gradual change of enstatite into the hydrous combination. The specific gravity of our enstatite is $3 \cdot 153$. The composition is as follows:-

$$
\begin{array}{lr}
\mathrm{SiO}_{2}=58 \cdot 00 & \mathrm{O}=30 \cdot 93 \\
\mathrm{Al}_{2} \mathrm{O}_{3}=1.35 & " \quad 0.63 \\
\mathrm{FeO}=3 \cdot 16 & " \quad 0 \cdot 70 \\
\mathrm{MgO}=36.91 & " 14.76 \\
\mathrm{H}_{2} \mathrm{O}=0.80 &
\end{array}
$$

These numbers resemble closely the composition of the Moravian specimen from the Zdjar Mountain, and those of the cosmical enstatites from Bishopville and Busti.

We also analyzed the steatitic crust, whose specific gravity $=2 \cdot 867$.

$$
\begin{aligned}
& \mathrm{SiO}_{2}=57 \cdot 62 \\
& \mathrm{Al}_{2} \mathrm{O}_{3}=1 \cdot 48 \\
& \mathrm{FeO}=1 \cdot 96 \\
& \mathrm{CaO}=0 \cdot 12 \\
& \mathrm{MgO}=34 \cdot 72 \\
& \mathrm{H}_{2} \mathrm{O}=4 \cdot 38
\end{aligned}
$$

So that the only change is the introduction of water. 
Considerable difficulties present themselves in the optical investigation of the Kjorrestad enstatite, arising from the perfect cleavages and the imperfect transparency. Professor Des Cloiseaux had the kindness to undertake the research, and determined the crystalline system from the optical character to be rhombic. It was done at a time when we were still in doubt concerning the form, and especially as we had not yet reduced the forms of the Kjorrestad crystals to those of bronzite and enstatite.

According to Professor Des Cloiseaux, the optical axes lie in the brachypinakoid. The acute positive bisectrix is parallel to the edge of the vertical prism. A plate cut normally to this edge gave (in oil):-

$$
\begin{aligned}
& \text { Right hyperbola to the normal } 3 \frac{0}{7} 30^{\prime} \\
& \text { Left " " } 2 \mathrm{H}_{a . r}=\frac{41 \quad 0}{78} 30
\end{aligned}
$$

Most of the crystals, as already mentioned, show a remarkable deformity, which consists in a dislocation or turning (round the makrodiagonal as axis) of all the faces forming the summit. The brachydiagonal becomes, to all appearance, klinoaxis. Whilst the crystals show, in consequence of this deformity, an asymmetric form on both sides of the macrodiagonal plane, the brachydiagonal plane becomes the face of symmetry. It is difficult to believe them of a rhombic character on looking at only a few of these crystals. But examining more of them, we get convinced, even without measuring, that the degree of the dislocation is different in each crystal, and that the whole phenomenon is to be reduced to perturbations.

But all the crystals are not deformed: some of them are of pure rhomboidal character; and these allow a crystallographic identification with the enstatite of Breitenbach (following von Lang, Sitzungsber. Ak. Wien, vol. lix. 2. Abth. Aprilheft, Jahrg. 1869), and with the hypersthene from the Rocher du Capucin in Montdore and from the lake of Laach (Des Cloiseaux, Manuel de Minéralogie, vol. ii. pp. xiv-xviii ; vom Rath, Pogg. Ann. vol. cxxxviii. p. 529, and vol. clii. p. 29).

In order to be able to compare the crystals of the three above-mentioned localities, we have drawn in the figures $1,1 a$, $2,2 a, 3,3 a$ the crystals of Breitenbach (meteoric), Laach, and Rocher du Capucin. the

We choose as the primitive form the pyramid measuring in 
On the enstatite On the hypersthene of Breitenbach. of Laach.

Makrodiagonal edge $=125^{\circ} 5 \dot{2}$

Brachydiagonal edge $=12736$

$125^{\circ} 58 \frac{1}{2}$

Lateral edge $\cdot=7842$

$12738 \frac{1}{2}$

$7834 \frac{1}{2}$

These angles give the following axis :-

$a$ (brachydiagonal) $: b$ (macrodiagonal) $: c$ (vertical) $=0.97016: 1: 0.57097$

for the Breitenbach meteoric enstatite, or

$$
=0.971326: 1: 0.57000
$$

for the hypersthene of Laach.

The faces represented in the figures receive the following formula if we refer to the preceding axes:-

Des Cloiseaux. von Lang.

$$
\begin{aligned}
& o=(a: b: c), \mathrm{P} \quad \ldots \ldots \ldots \ldots \ldots . \ldots b^{\frac{1}{2}} \quad 112 \\
& i=\left(\frac{1}{2} a: b: c\right), 2 \overline{\mathrm{P}} 2 \ldots \ldots \ldots \ldots \ldots . \ldots a_{3} \quad 122 \\
& e=(a: 2 b: c), \overrightarrow{\mathrm{P}} 2 \ldots \ldots \ldots \ldots \ldots . . . \ldots n \\
& u=\left(a: \frac{2}{3} b: c\right), \frac{3}{2} \breve{P}_{2}^{3} \ldots \ldots \ldots \ldots \ldots, x \\
& x=\left(\frac{1}{2} a: \frac{1}{2} b: c\right), 2 \mathrm{P} \ldots \ldots \ldots \ldots \ldots . . .111 \\
& m=(a: b: \infty c), \infty \mathrm{P} \ldots \ldots \ldots \ldots \ldots . \ldots . \ldots \\
& n=(2 a: b: \infty c), \infty \breve{\mathrm{P} 2} \ldots \ldots \ldots \ldots . . . \quad 120 \\
& z=(a: 2 b: \infty c), \infty \overline{\mathrm{P}} 2 \\
& h=(\infty a: 4 b: c), \frac{1}{4} \breve{\mathrm{P}} \infty \ldots \ldots \ldots . . . e^{4} \\
& k=(\infty a: 2 b: c), \frac{1}{2} \breve{\mathrm{P}} \infty \ldots \ldots \ldots \ldots e^{2} \quad 104 \\
& a=(a: \infty b: \infty c), \infty \overline{\mathrm{P}} \infty \ldots \ldots \ldots . . . h^{1} \quad 010 \\
& b=(\infty a: b: \infty c), \infty \breve{\mathrm{P}} \infty \ldots \ldots \ldots g^{1} \quad 100 \\
& c=(\infty a: \infty b: c), 0 \mathrm{P} \ldots \ldots \ldots \ldots . . . . . p \quad 001
\end{aligned}
$$

There was only one angle on the crystals of Kjorrestad which could be measured with the reflection-goniometer - that is to say, the angle of the two cleavage-faces, $=91^{\circ} 25^{\prime}-91^{\circ} 40^{\prime}$. Von Lang determined this angle on the enstatite of Breitenbach $=91^{\circ} 44^{\prime}$. On the hypersthene of Laach $\mathrm{I}$ found this angle $=91^{\circ} 40^{\prime} ;$ whilst Des Cloiseaux gives the angle $=91^{\circ} 32 \frac{1}{2}^{\prime}$ for the hypersthene of Capucin, as the mean of several measures. All the other angles of the Kjorrestad crystals can only be measured with the contact-goniometer, and even that only approximately, in consequence of the striation, the arching, oscillation, and repetition of the faces, sometimes already decomposed.

One of the largest crystals in the Museum of Christiania 
384 MM. W. C. Brögger and G. vom Rath on certain

(measuring along the axis $a 12$ centims., along the axis $b 20$ centims.) shows undoubted rhombic symmetry. We have determined the following faces:-

$$
\begin{aligned}
& e=(a: 2 b: c), \quad \mathrm{P} 2, \\
& \epsilon=\left(a: \frac{3}{4} b: c\right), \quad \frac{4}{3} \breve{\mathrm{P}}^{4} . \\
& \psi=(\infty a: 6 b: c), \frac{1}{6} \mathrm{P} \infty, \\
& \gamma=\left(\infty a: \frac{7}{2} b: c\right), \frac{2}{7} \breve{\mathrm{P}} \infty, \\
& \kappa=(\infty a: 2 b: c), \frac{1}{2} \breve{\mathrm{P}} \infty, \\
& q=\left(\infty a: \frac{3}{2} b: c\right),{ }_{3} \breve{\mathrm{P}} \infty, \\
& m=(a: b: \infty c), \infty \mathrm{P}, \\
& a=(a: \infty b: \infty c) \infty \overline{\mathrm{P}} \infty, \\
& b=(\infty a: b: \infty c), \infty \breve{\mathrm{P}} \infty, \\
& c=(\infty a: \infty b: c), 0 \mathrm{P} .
\end{aligned}
$$

\begin{tabular}{|c|c|c|}
\hline$m: m^{\prime}$ & $=88^{\circ} \quad 0$ & $88^{\circ} 16$ \\
\hline$k: b$ & $=10550$ & 10556 \\
\hline$q: b$ & $=111 \quad 0$ & $11050 \frac{1}{2}$ \\
\hline$\gamma: b$ & $=9930$ & $9916^{\circ}$ \\
\hline$\psi: b$ & $=9530$ & 9526 \\
\hline$\epsilon: k$ & $=15030$ & 14731 \\
\hline$\epsilon: b$ & $=12230$ & 12316 \\
\hline$e: b$ & $=105 \quad 0$ & 10349 \\
\hline$e: a$ & $=11930$ & 11931 \\
\hline$e: \gamma$ & $=15145$ & $149 \quad 49$ \\
\hline$e: \psi$ & $=150 \quad 0$ & 14851 \\
\hline$e: k$ & $=152 \quad 0$ & $150 \quad 29 \frac{2}{3}$ \\
\hline
\end{tabular}

The faces denoted by Latin letters are already known on the enstatite from Breitenbach and on the hypersthenes from Laach and Capucin. The faces denoted by Greek letters are new. The fig. 4 represents the crystal in question with all deformities. The following angles were measured with the contact-goniometer. It will be seen that they compare satisfactorily with the values calculated from the elements of the Breitenbach enstatite.

Measured.

Only two of these measurements $(\epsilon: k$ and $e: \gamma)$ show a considerable divergence from the calculated angles. It is to be explained by the difficulty and uncertainty involved in measuring faces perturbated by oscillation and vaulting. 
Also it is to be noticed that the crystal was measured at Christiania, and that the faces denoted by Greek letters were determined at Bonn. Having in view the imperfections of the faces, it would not have been possible to obtain measurements more nearly approaching to the calculated angles.

Fig. 5 represents a crystal of the Museum of Bonn : 5 is a portrait of the crystal ; $5 a$ and $5 b$ are more ideal representations. We have the following combination :-

$$
\begin{aligned}
& \tau=\left(\frac{3}{2} a: \frac{3}{2} b: c\right), \frac{2}{3} \mathrm{P}, \\
& k=(\infty a: 2 b: c), \frac{1}{2} \breve{\mathrm{P}} \infty \text {, } \\
& q=\left(\infty a: \frac{3}{2} b: c\right), \stackrel{2}{3} \breve{P} \infty \text {, } \\
& \psi=(\infty a: 6 b: c), \frac{1}{6} \breve{\mathrm{P}} \infty \text {, } \\
& m=(a: b: \infty c), \quad \infty \mathrm{P}, \\
& b=(\infty a: b: \infty c), \infty \breve{\mathrm{P}} \infty \text {. } \\
& \text { Measured. Calculated. } \\
& \begin{array}{lr}
m: m^{\prime}=88 & 8816 \\
k: b=106 & 10556 \\
q: b=11030 & 110501 \\
\psi: k=169 & 16930 \\
\tau: q= & 159512 \\
\tau: m=120 & 11840
\end{array}
\end{aligned}
$$

We remark already a certain asymmetry in this crystal, as is to be seen in the following measurements:-

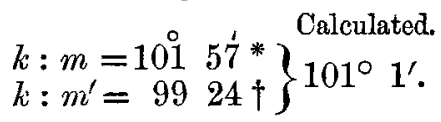

The pyramid $\tau$, not yet observed in enstatite and hypersthene, has been determined by the horizontal edges formed with the prism $m$ as well as through the parallelism of the edges $\tau: q: \tau^{\prime}$. The dimensions of that crystal are-altitude 7 centims., breadth 8 centims., thickness 9 centims. The crystal is broken parallel to two prismatic faces.

Fig. 6 is very much like the preceding :

Measured. Calculated.

$$
\begin{array}{rlrl}
m: m^{\prime} & =8 \stackrel{\circ}{8} & \\
\tau: m=118 & 118 & 40 \\
\tau: a=109 \frac{3}{4} & 110 \quad 8 \frac{1}{3}
\end{array}
$$

* Mean of ten measurements between $101 \frac{30}{4}$ and $102^{\circ}$.

$\dagger$ Mean of ten measurements between $994^{\circ}$ and $992^{\circ}$.

Phil. Mag. S. 5. Vol. 2. No. 12. Nor. 1876. 
Here also the face $k$ is a little dislocated:

$$
\begin{aligned}
& k: m=103^{\circ} \quad \dot{0} \quad 101 \dot{1} \\
& k: m^{\prime}=99 \quad 45
\end{aligned}
$$

It is possible, even easy, to reduce the above-mentioned crystals to the form of enstatite, as the perturbations which produce a monoclinic appearance are only 1 or a few degrees. On other crystals it is impossible without making too arbitrary assumptions, because the differences between the homologous edges are as great as 7 degrees, even more in some cases. The two large crystals of the Bonn Museum have such a habit. One of them (see fig. 7) allows pretty exact measurements, If we had had only this single one, we should not have dared to assign it to the rhombic system of enstatite; and yet even here no doubt remains that the irregularity is due to perturbations only. We acquire this conviction, as well by comparison with the more regular specimens as by an exact study of the perturbed crystal itself if we try to reduce it to the monoclinic system. We get in this case no simple symbols, and we are obliged to take different axial elements for nearly every crystal. The best-formed specimen of the Bonn collection gave the following angles (fig. 7):-

$$
\begin{aligned}
& \left.m: m^{\prime} \text { (over } b\right)=89^{\circ} 40^{\prime}, \\
& m: \chi=109^{\circ}, \\
& m^{\prime}: \chi=102^{\circ} .
\end{aligned}
$$

If we regard $m$ as prism $\infty \mathrm{P}, \chi$ as klinodome $(\mathrm{P} \infty)$, we obtain the following elements:-

$$
a: b: c=0.99798: 1: 0.41387 ;
$$

obliquity of axis $(\beta)=94^{\circ} 57^{\prime}$.

For the face $\sigma$ we cannot get any more simple symbols than $\left(\frac{3}{4} a^{\prime}: b: \frac{3}{4} c\right), \frac{4}{3} \mathrm{P} \frac{4}{3}$.

Supposing this formula, we find-

Calculated.

$$
\begin{aligned}
& m^{\prime}: \sigma=121 \quad 56 \frac{1}{2} \\
& \chi: \sigma=152 \quad 0
\end{aligned}
$$

Measured.

Comparison with the other crystals of pseudomonoclinic habit leaves no doubt that the face $\chi$ is identical with the brachydome $q=2 \breve{3} \breve{\mathrm{P}} \infty$ of the normal crystals, and that the difference of the angles $\chi: m^{\prime}=102^{\circ}, \chi: m=109^{\circ}$ is to be explained by the dislocation of all the faces forming the summit. The angle $q: m=104^{\circ} 202^{\prime}$ (calculated on the supposition of the rhombic elements of the Breitenbach enstatite) corresponds to 
Messrs. Clayden and Heycock on the Spectra of Indium. 387

both angles. The real symbol is also to be found for the disturbed face $\sigma$; reduced to the system of the enstatite, it has the symbol $\left(a: \frac{3}{2} b: c\right), \overline{\mathrm{P}}_{\frac{3}{2}}$. For the inclination of this face we have

$$
m^{\prime}: \sigma=124^{\circ} 16^{\prime} ; \chi: \sigma=151^{\circ} 11^{\prime} \text {. }
$$

We must compare these angles with the above in order to recognize the degree of perturbation. There are yet several other faces on the enstatite crystals from Kjorrestad, the symbols of which, in consequence of their imperfections, cannot be definitely determined. "Such faces are not indicated by a letter in our figure. This richness of faces recalls to mind the meteoric enstatite of the Breitenbach iron, which were determined by von Lang's sagacity. The cause of the remarkable monoclinic formation of the Norwegian enstatite is quite hidden. The first thought may be that it is the result of pressure. But that explanation must be surrendered if we observe that the monoclinic dislocation is only to be seen in the faces of the summit, and never in the vertical faces. So this anomaly seems to have its origin in crystallonomic causes. The exhausted apatite-mine of Kjorrestad is hitherto the only known locality of these enstatite giants. No doubt implanted enstatite crystals will be found in other plutonic localities. If we shall there be able to observe the crystals not merely among the materials thrown away, but also in their natural position in situ, we may possibly find a solution for the dislocation of the terminating faces, which is at present an enigma.

Bonn, October 4, 1876.

XLVII. The Spectra of Indium. By ARTHUR W. Clayden, B.A., and Charles T. Heycock*.

QOME time ago, while working at a course of lectures on 5 spectrum-analysis, given by the Professor of Chemistry, we noticed that the spectrum of indium, as obtained by passing the spark from an induction-coil between points of the metal, differed from that given in the various books on the subject. Instead of the three lines expected, we found sixteen.

During the past summer we have investigated the matter, with the following results."

When the spark is used to decompose and volatilize the chloride of the metal, the spectrum ordinarily given in the books, namely two lines in the indigo and one in the violet, is seen. Thalén gives the following measurements for these4532,4509 , and 4101 ; but we are inclined to think 4510 is nearer the truth than 4509 .

* Communicated by the Authors.

$2 \mathrm{C} 2$ 

